\title{
Anti-Obesity and Hypolipidemic Effects of Ajwa Date Seed Compared to Simvastatin in Butter Fed Dyslipidemic Rats
}

\author{
${ }^{1}$ Farooq Sultan, ${ }^{2}$ Saba Anwar, ${ }^{3}$ Saadia Shahzad Alam, ${ }^{4}$ Hassan Farooq, ${ }^{1}$ Ajmal Afzal, \\ ${ }^{5}$ Moneeb Ashraf \\ ${ }^{I}$ Department of Pharmacology, Gujranwala Medical College, Gujranwala \\ ${ }^{2}$ Women Medical Officer, Rural Health Centre Hadali Khushab \\ ${ }^{3}$ Department of Pharmacology, Shaikh Zayed Medical Complex, Lahore. \\ ${ }^{4}$ Department of Pharmacology, Khawaja Muhammad Safdar Medical College, Sialkot \\ ${ }^{5}$ Department of Pharmacology, Postgraduate Medical Institute, Lahore
}



\section{ABSTRACT}

Introduction: Hyperlipidemia results into various complications like atherosclerosis, Coronary Heart Disease, Stroke and Fatty Liver Disease. Due to serious side effects of current lipid lowering therapies, research has shifted towards natural products. Aims \& Objectives: To evaluate the hypolipidemic effects of ajwa date seed in comparison to modern hypolipidemic drug simvastatin. Place and duration of study: A 36 days study was conducted at the Animal House \& Experimental Research Lab of UHS, Lahore. Material \& Methods: Total 40 rats were segregated into 5 groups having 8 rats each. All groups except Group 1 healthy control were administered high fat diet for 36 days. Group 2 was maintained as disease control group. Group 3,4 and 5 were administered simvastatin $10 \mathrm{mg} / \mathrm{kg} /$ day, aqueous ADSE $8 \mathrm{ml} / \mathrm{kg} /$ dayand combination of both drugs (in half doses) respectively for last 21 days of study. Weight measurement and Lipid profile was performed at day 0,15 and 36 of study. Data was entered on SPSS 23.0 software and analyzed by one way ANOVA and post hoc tukey's tests. P-value of less than 0.05 was considered significant. Results: Healthy controls showed normal bodyweight, and lipid profile while disease control showed significant derangement of both parameters after consuming high fat diet for 15 days. In comparison with disease control, treatment with standard drug Simvastatin $10 \mathrm{mg} / \mathrm{kg} / \mathrm{day}$ for 21 days resulted in less weight gain and decreased the serum TC, TG and LDL by $3 \%, 14 \%$ and $45 \%$ respectively. Aqueous ADSE administration also caused a similar pattern of lesser weight gain and corresponding decrease in serum TC and TG levels by $4 \%$ and $34 \%$ respectively. Half dose combination of both drugs also showed corresponding effect as less weight gain was noticed with only significant improvement in serum TG and VLDL parameters of lipid profile. These effects were less prominent than with full doses. P-value was less than 0.05 which is significant. Conclusion: Ajwa date seed has anti obesity and hypolipidemic effect as compared to Simvastatin our standard drug. Therefore ajwa date seed has potential as a weight lowering agent and as an effective alternative to Simvastatin for treatment of hyperlipidemia.

Key words: Ajwa date seed extract (ADSE), Hyperlipidemia, Simvastatin

\section{INTRODUCTION}

$\mathrm{H}_{3}$ yperlipidemia or dyslipidemia is a metabolic disorder characterized by elevated levels of serum total cholesterol (TC), triglycerides (TG) and low density lipoproteins (LDL) or reduced levels of high density lipoproteins (HDL). ${ }^{1}$ Abnormal or elevated levels of lipids in the blood may cast untoward effects on the body. These abnormal levels of lipids result in diseases such as atherosclerosis, stroke, cardiovascular diseases, renovascular diseases, obesity and non-alcoholic fatty liver disease. ${ }^{2}$ The Global Health Observatory (GHO) data of World
Health Organization (WHO) in 2008 shows that the prevalence of elevated total cholesterol among adults was $39 \%$ worldwide and $29 \%$ in South East Asian region. ${ }^{3}$ According to the National Health Survey of Pakistan, 24 percent of urban males of Pakistan are suffering from high serum cholesterol levels. $^{4}$

Statins are the most widely prescribed and the most effective agents for the treatment of hyperlipidemia and its associated complications. ${ }^{5}$ They are the inhibitors of 3-hydroxy 3-methlylglutaryl coenzyme A (HMG-CoA) reductase enzyme which catalyzes the rate limiting step of cholesterol synthesis. ${ }^{6}$ 
Simvastatin is one of the FDA approved statin drugs. Owing to the adverse effects of statins, considerable research interest has been shifted towards the hypolipidemic effects of natural products like Phoenix dactylifera (Palm Date). It is being used as diet by humans for almost 6000 years, hence, one of the oldest historical plants on earth. Ajwa is one type of Palm Dates which are only cultivated in Al-Madinah Al-Munawara, Saudi Arabia. It has special value for Muslims as many Ahadiths are there to highlight its importance. ${ }^{7}$ Ajwa date has been used as diet and remedy for various diseases. Date fruit called Pericarp is composed of constituents which are of high nutritional value. These include carbohydrate, vitamins, fatty acids, minerals, dietary fibers and various salts.

In contrast, the date seed is considered usually a waste product. Recently, it has been mostly used as a feed for animals like camel, sheep, poultry and cattle. ${ }^{8}$ Limited research has been done on the benefits of the date seeds. According to a study, Ajwa date seed was found to contain almost $19 \%$ crude fiber, $7.8 \%$ crude proteins and $9.8 \%$ crude fat. It also contained $62 \%$ nitrogen Free Extract (NFE) which denotes amount of carbohydrates, starches and sugars. Ajwa date seed was also enriched with various minerals like phosphorous, potassium, zinc, boron, iron, magnesium, copper, calcium and sodium. HPLC profile of Ajwa date seed also showed promising antioxidant content containing high amount of phenolic compounds and flavonoids with antioxidative potential. ${ }^{9}$ Being a rich source of antioxidants, Ajwa date seed is believed to possess vital role in the prevention and treatment of various diseases. Ajwa Date Seed Extract exhibited significant improvement in the lipid profile of diabetes induced rats. ${ }^{10}$ In a murine model, improvement in the hematological, hepatic and renal parameters were detected after treatment with Ajwa date seed extract. ${ }^{11}$ In another study, date seed extract was found to improve the symptoms in the rats in which induction of focal cerebral ischemia was done through occlusion of middle cerebral artery. ${ }^{12}$ Most of these effects are attributed to the antioxidant potential of Ajwa date seeds. The current research was undertaken to investigate the antiobesity and hypolipidemic effects of Ajwa date seed in comparison to Simvastatin.

\section{MATERIAL AND METHODS}

\section{Experimental Setup:}

A 36 day Study was conducted at Animal house and Experimental Research Laboratory of UHS, Lahore.
Biochemical tests of lipid profile were done at Biochemistry Lab of Shaikh Zayed Hospital, Lahore.

Animals:

40 Healthy male albino rats weighing in the range of 100-150gms were purchased from University of Veterinary and Animal Sciences, Lahore. They were segregated through lottery method into 5 groups with 8 animals in each group. The animals were kept in the animal house at UHS, Lahore and were given free access to standard laboratory diet.

\section{Animal diet:}

Standard animal diet was procured from the University of Veterniary and Animal Sciences (UVAS) Lahore. For preparation of high fat diet (HFD), Adam's butter 250grams was added to standard laboratory diet to make 1000 grams of high fat diet (HFD).

\section{Plant material:}

Imported Ajwa dates of Madina Al-Manawara were purchased from Irum Mart, Walton Road, Lahore. Date seeds of above mentioned mart were used throughout the experiment.

\section{Aqueous Ajwa Date Seed Extract (ADSE)} preparation:

Fruit pulp was removed and seeds were separated, washed and dried at room temperature for 2-3 days. Dry seeds were roasted in the Home Coffee Roasting Machine for $15 \mathrm{~min}$ at $220^{\circ} \mathrm{C}$ and then cooled to room temperature. ${ }^{9}$ Roasted seeds were crushed into small pieces and powder was made after grinding in the coffee grinder. 100 grams of seed powder was soaked in 1 liter of distilled water and kept at $4^{\circ} \mathrm{C}$ for 48 hours with intermittent stirring. The extract was filtered through cotton after 48 hours and the supernatant was further used in the research project. Dose of aqueous Ajwa Date Seed Extract was administered in amount of $8 \mathrm{ml} / \mathrm{kg} /$ day. ${ }^{13}$ According to the reference article, this dose of ADSE produced the most favorable effects without any evident adverse effects in rats.

\section{Chemicals and Drugs:}

Simvastatin 10mg tablet was purchased from Clinix Pharmacy Jail Road, Lahore. It was administered orally suspended in distilled water in the dose of $10 \mathrm{mg} / \mathrm{kg} / \mathrm{day}$.

\section{Grouping of Animals:}

Animals were segregated into 5 groups with 8 rats in each group.

Healthy Control group (Group 1) animals were given the normal laboratory diet for the entire study period of 36 days, and they were not treated.

Group 2 was fed butter for 36 days and no treatment was administered 
All other groups (3-5) were butter fed for entire study period of 36 days and administered drugs for 21 days by gastric gavage orally after the induction of dyslipidemia at day 15.

Group 3 was administered Simvastatin $10 \mathrm{mg} /$ $\mathrm{kg} /$ day.

Group 4 was administered Ajwa Date Seed extract $8 \mathrm{ml} / \mathrm{kg} / \mathrm{day}$.

Group 5 was administered a combination of Simvastatin $5 \mathrm{mg} / \mathrm{kg} /$ day and Ajwa Date Seed extract $4 \mathrm{ml} / \mathrm{kg} /$ day.

Biochemical tests: Blood sampling was done at day 0,15 and 36 through intracardiac puncture. Serum was collected by centrifugation and lipid profile (serum TC, TG, LDL, VLDL and HDL) was performed by using biochemical kits of Siemens Company.

Statistical Analysis: Data was analyzed using SPSS version 23.0. Comparison among groups was made by use of one way ANOVA and posthoc Tukey's test.

G 1: Healthy Control

G 2: Disease Control

G 3: Simvastatin $10 \mathrm{mg} / \mathrm{kg} /$ day

G 4: ADSE $8 \mathrm{ml} / \mathrm{kg} /$ day

G 5: Simvastatin $5 \mathrm{mg} / \mathrm{kg} /$ day

+ ADSE 4ml $/ \mathrm{kg} /$ day

* (Significant)

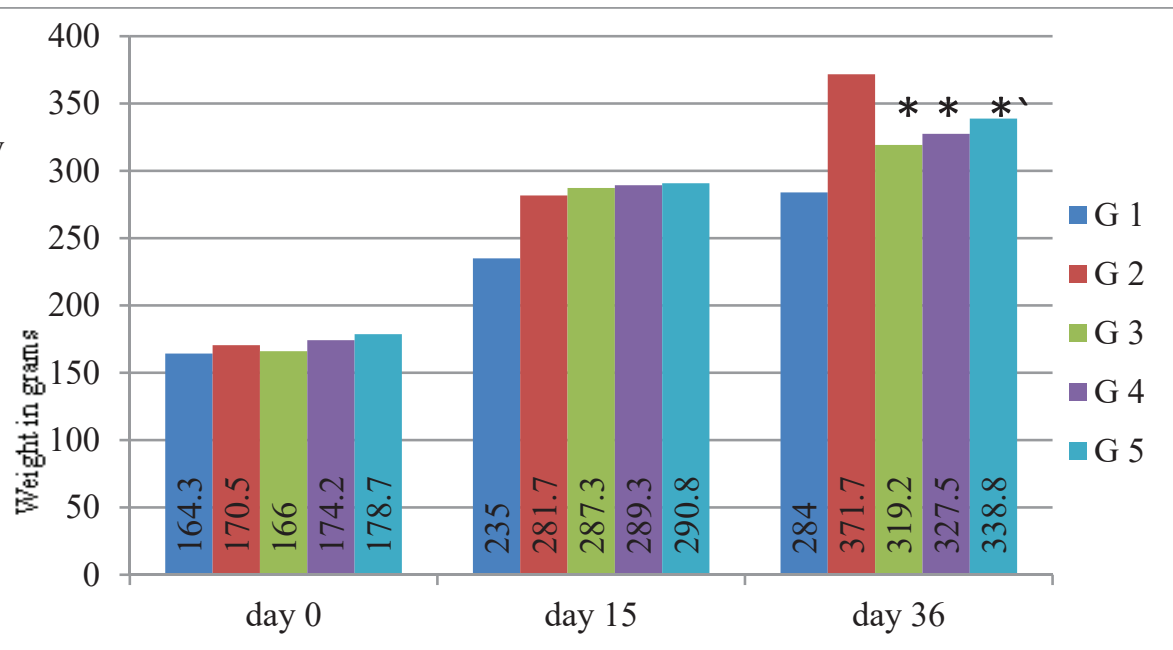

Fig-1: Body weight grams of groups 1, 2, 3, 4 and 5 on day 0,15 and $36(n=8)$

G 1: Healthy Control

G 2: Disease Control

G 3: Simvastatin $10 \mathrm{mg} / \mathrm{kg} / \mathrm{day}$

G 4: $\operatorname{ADSE} 8 \mathrm{ml} / \mathrm{kg} / \mathrm{day}$

G 5: Simvastatin $5 \mathrm{mg} / \mathrm{kg} /$ day

+ ADSE $4 \mathrm{ml} / \mathrm{kg} /$ day

* (Significant)

\section{RESULTS}

At the start of study, body weight of all animals was in the range of 150-200 grams. All parameters of lipid profile (serum TC, TG, LDL, VLDL and HDL) were also in the normal range. After butter feeding for 15 days, there was significant increase in weight and derangement of lipid profile. Treatment with Simvastatin $10 \mathrm{mg} / \mathrm{kg} /$ day and aqueous ADSE $8 \mathrm{ml} / \mathrm{kg} /$ day prevented significant weight gain and brought the deranged lipid profile parametes towards normalization as compared to disease control group. Combination of drugs (simvastatin $5 \mathrm{mg} / \mathrm{kg} /$ day + ADSE $4 \mathrm{ml} / \mathrm{kg} /$ day) also improved all parameters but significant effects were found only on weight gain, serum TG and VLDL parameters when compared with disease control group. P-value was less than 0.05 which was considered significant. Results are displayed in the following figures as mean values. 
G 1: Healthy Control

G 2: Disease Control

G 3: Simvastatin $10 \mathrm{mg} / \mathrm{kg} /$ day

G 4: ADSE $8 \mathrm{ml} / \mathrm{kg} / \mathrm{day}$

G 5: Simvastatin $5 \mathrm{mg} / \mathrm{kg} / \mathrm{day}$

+ ADSE $4 \mathrm{ml} / \mathrm{kg} / \mathrm{day}$

* (Significant)

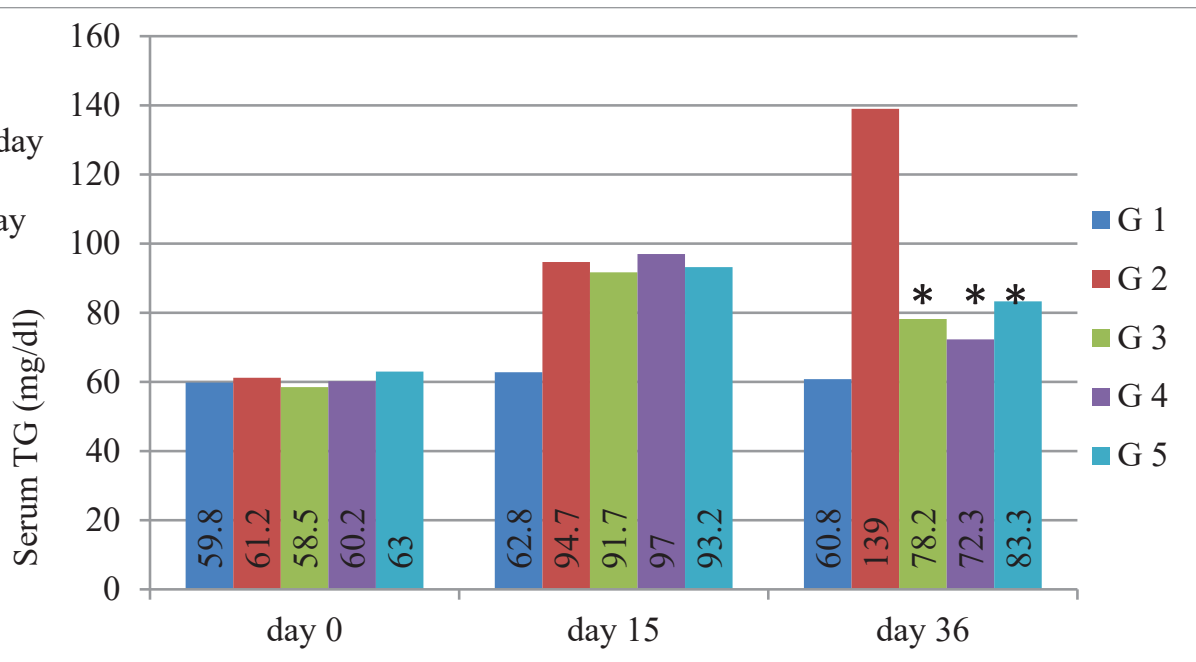

Fig-3: Serum TG (mg/dl) of groups $1,2,3,4$ and 5 on day 0,15 and $36(n=8)$

G 1: Healthy Control

G 2: Disease Control

G 3: Simvastatin $10 \mathrm{mg} / \mathrm{kg} /$ day 20

G 4: $\operatorname{ADSE} 8 \mathrm{ml} / \mathrm{kg} / \mathrm{day}$

G 5: Simvastatin $5 \mathrm{mg} / \mathrm{kg} / \mathrm{day}$

+ ADSE $4 \mathrm{ml} / \mathrm{kg} / \mathrm{day}$

* (Significant)

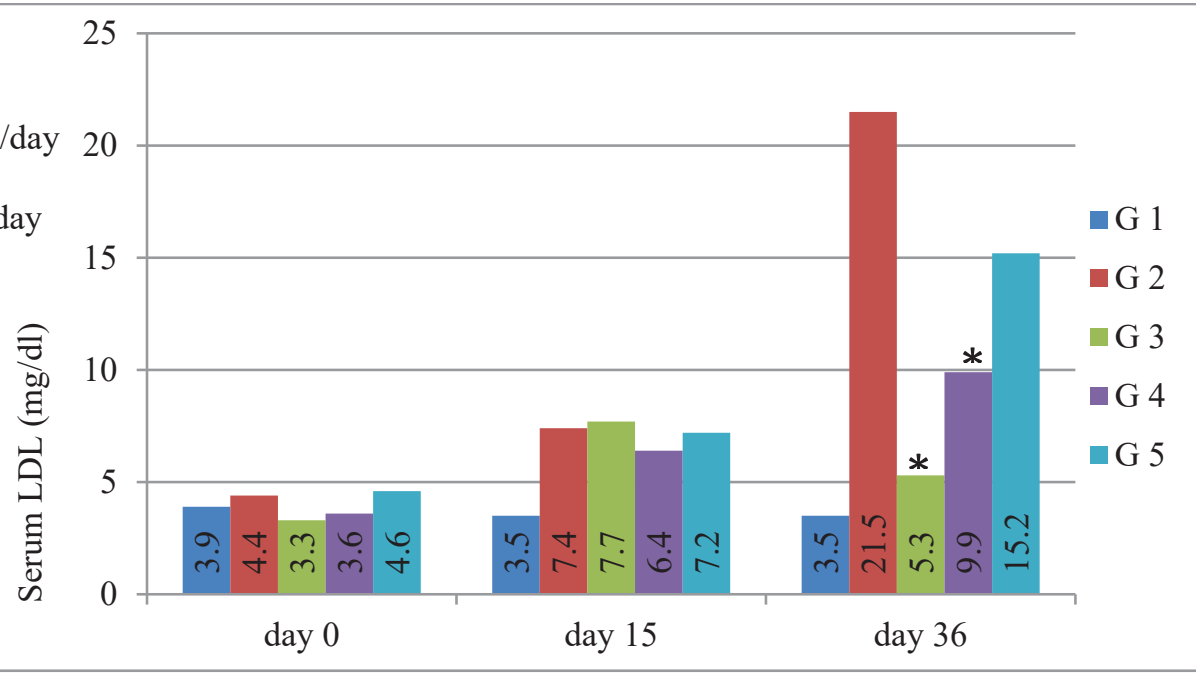

Fig-4: Serum LDL (mg/dl) of groups 1, 2, 3, 4 and 5 on day 0,15 and $36(n=8)$

G 1: Healthy Control

G 2: Disease Control

G 3: Simvastatin $10 \mathrm{mg} / \mathrm{kg} / \mathrm{day}$

G 4: ADSE $8 \mathrm{ml} / \mathrm{kg} / \mathrm{day}$

G 5: Simvastatin $5 \mathrm{mg} / \mathrm{kg} /$ day

+ ADSE $4 \mathrm{ml} / \mathrm{kg} /$ day

* (Significant)

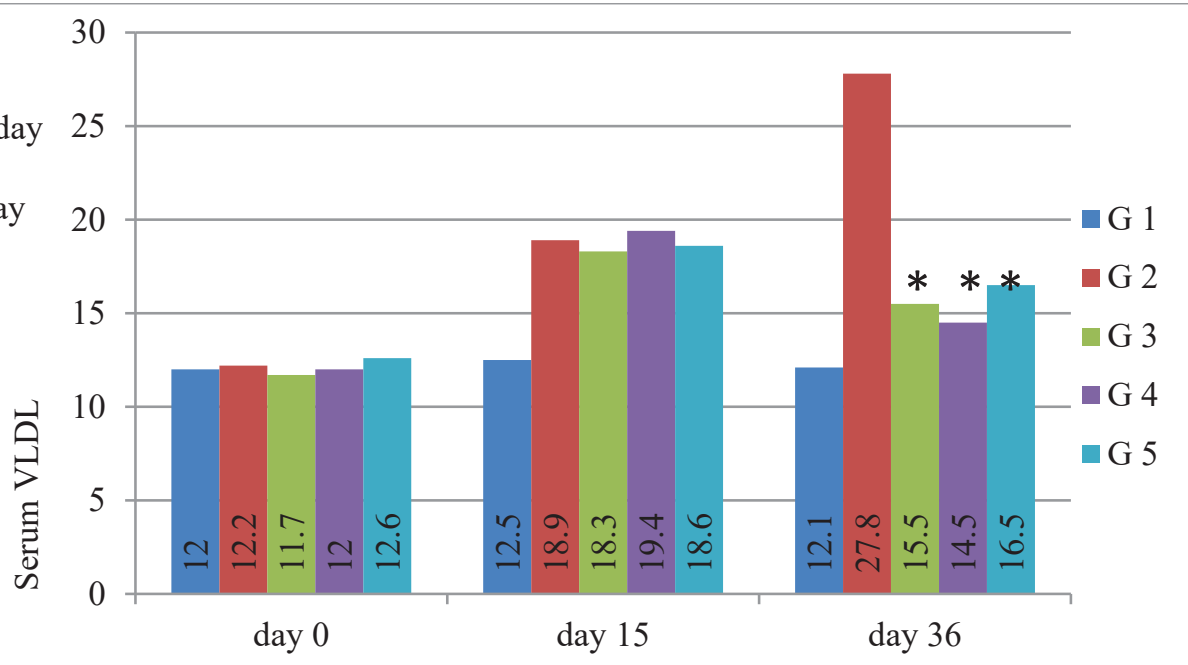

Fig-5: Serum VLDL (mg/dl) of groups 1, 2, 3, 4 and 5 on day 0,15 and $36(n=8)$ 


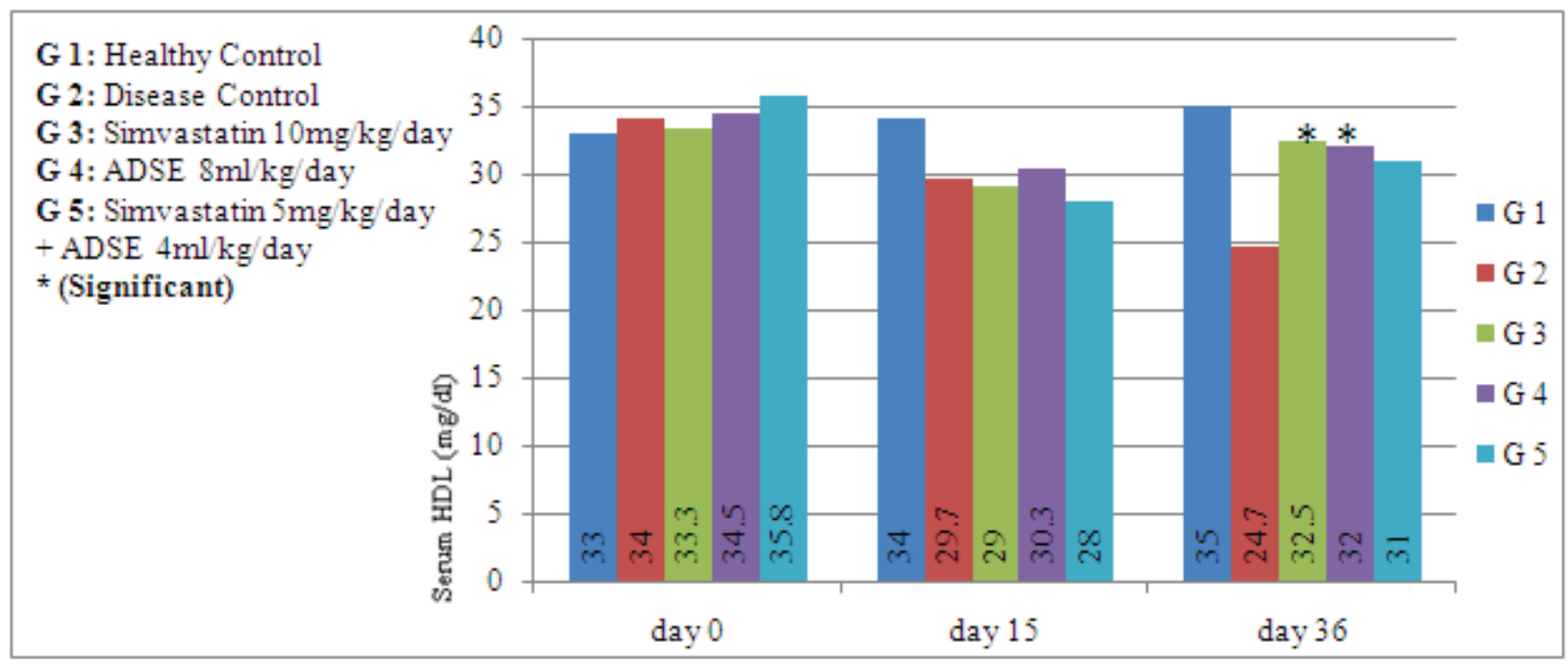

Fig-6: Serum HDL (mg/dl) of groups 1, 2, 3, 4 and 5 on day 0,15 and $36(n=8)$

\section{DISCUSSION}

In current research work, impact of aqueous Ajwa date seed extract (ADSE) 8ml/kg/day, Simvastatin $10 \mathrm{mg} / \mathrm{kg} /$ day and their combination in half doses on hyperlipidemia due to butter feeding was assessed through changes in body weight and biochemical parameters of serum TC, TG, LDL, VLDL and HDL.

On day 15 , body weight of butter fed groups (2-5) increased significantly in the range of $39 \%-43 \%$. This was in conformation with another study in which weight gain was $48 \%$ after 21 days consumption of butter containing high fat diet. ${ }^{14} \mathrm{At}$ the end of study, group 2 showed highest increase in the weight by $24 \%$ as it was given no treatment.

However, intervention with Simvastatin $10 \mathrm{mg} / \mathrm{kg} /$ day resulted in controlling weight gain of group 3 by $14 \%$ as compared to disease control group. P-value was 0.000 which shows significant effects of Simvastatin on weight gain. Weight controlling effect of Simvastatin is due to reduction in adiposity by exerting anti-inflammatory effects and altering the adipocyte differentiation in adipose tissue. ${ }^{15}$

Current study also exhibited that administration of Ajwa date seed $8 \mathrm{ml} / \mathrm{kg} /$ day to produced significantly less weight gain than the disease control group. This could be due to the antioxidants Vitamin C, zinc, copper, polyphenols and flavonoids contained in the seeds which hampered the oxidative stress involved in obesity. ${ }^{9,16}$ No other study could be found to compare the results of Ajwa date seed on weight increase in response to high fat diet.

Butter feeding for 15 days significantly deranged the all parameters of lipid profile (TC, TG, LDL,
VLDL and HDL) of groups 2-5 as compared to the healthy control group. On the conclusion of experiment, disease control group had most significant derangement of lipid profile as it was given no treatment. Continuous butter feeding for 36 days caused excessive lipid absorption from intestines and hyperlipidemia. ${ }^{17}$

Treatment with Simvastatin $10 \mathrm{mg} / \mathrm{kg} /$ day for 21 days reduced the serum TC, TG, LDL and VLDL by $3 \%, 14 \% .45 \%$ and $18 \%$ while increasing the serum HDL levels by $11 \%$. Effects of Simvastatin were significant when compared to disease control group as p-value was less than 0.05. Simvastatin is a known antihyperlipidemic drug. It interferes with hepatic cholesterol production by inhibiting the HMG CoA reductase enzyme which catalyzes the rate limiting step of cholesterol synthesis. In response, LDL receptors on the surface of hepatocytes are up regulated by genetic transcription to maintain hepatic cholesterol levels. It results in low lipid levels in blood. ${ }^{18}$ Effects of Simvastatin $10 \mathrm{mg} / \mathrm{kg} /$ day on lipid profile were validated in current study.

Interestingly aqueous ADSE $8 \mathrm{ml} / \mathrm{kg} /$ day showed comparable results to standard drug Simvastatin. At the end of study, it decreased the serum TC and TG levels by $4 \%$ and $34 \%$. P-value was less than 0.05 which shows significant association of ADSE with normalization of lipid profile parameters as compared to disease control group. This finding is in line with another study in which ADSE reduced the serum TC and TG in diabetic model of rats. ${ }^{10}$ Similarly, aqueous ADSE $8 \mathrm{ml} / \mathrm{kg} /$ day normalized the other parameters of lipid profile i.e. serum LDL, VLDL and HDL significantly as compared to disease control group. The reason could be that Ajwa date seed contains high amount of antioxidant 
compounds polyphenols (Gallic acid, Chlorogenic acid, Ferulic acid, Coumaric acid, Caffiec acid, Catechin and Querctin), and vitamin $\mathrm{C}$ which have been found in citrus peel extract as well. ${ }^{9}$ In a previous research, these antioxidant compounds reduced the activity of hepatic enzymes 3-hydroxy3-methyl-glutaryl-CoA (HMG CoA) reductase which is vital for cholesterol biosynthesis. ${ }^{19,20}$ They also inhibit the HMG CoA reductase enzyme through non-competitive inhibition through modification of binding site of enzyme resulting in blockage of enzyme-substrate complex. ${ }^{21}$ Polyphenols and vitamin $\mathrm{C}$ contained in Ajwa date seed may be responsible for decrease in hepatic cholesterol stores resulting in increased hepatic uptake of cholesterol from extra hepatic sources especially vascular system. It results in lowering of blood lipid levels. ${ }^{22}$ Quercetin blocks the transcription of several enzymes involved in the synthesis of fatty acids. ${ }^{23}$ Saponins are also present in Ajwa date seed which reduces absorption of lipids in intestines and causes inhibition of lipase enzyme. ${ }^{10}$

A combination of Simvastatin and Aqueous ADSE administered in half dose were also effective in improving all parameters of lipid profile through multiple lipid lowering mechanism described above. However, its effects were significant only on serum TG and VLDL which are more interdependent as compared to other lipid profile parameters.

\section{CONCLUSION}

These biochemical findings suggest an antiobesity and hypolipidemic role of aqueous ADSE $8 \mathrm{ml} / \mathrm{kg} /$ day and Simvastatin $10 \mathrm{mg} / \mathrm{kg} /$ day which shows that Ajwa date seed may be used an alternative to allopathic drugs. Half dose combination was less effective than individual effects of Simvastatin and aqueous ADSE which shows dose related effects of both drugs.

\section{REFERENCES}

1. Beyegue CN, Ngangoum RC, Kuate D, Ngondi J, Oben JE. Effect of Guibourtia tessmannii extracts on blood lipids and oxidative stress markers in triton WR 1339 and high fat diet induced hyperlipidemic rats. Biology and Medicine. 2012; 4(1):1.

2. Leiva A, Contreras-Duarte S, Amigo L, Sepúlveda E, Boric M, Quiñones V, et al. Gugulipid causes hypercholesterolemia leading to endothelial dysfunction, increased atherosclerosis, and premature death by ischemic heart disease in male mice. PloS one. 2017; 12(9):0184280.

3. World Health Organization. Raised cholesterol 2017. Available from:

http://www.who.int/gho/ncd/risk_factors/cholest erol_text/en/

4. Dodani S, Mistry R, Khwaja A, Farooqi M, Qureshi R, Kazmi K. Prevalence and awareness of risk factors and behaviours of coronary heart disease in an urban population of Karachi, the largest city of Pakistan: a community survey. Journal of public health. 2004; 26(3):245-9.

5. S Antonopoulos A, Margaritis M, Lee R, Channon K, Antoniades C. Statins as antiinflammatory agents in atherogenesis: molecular mechanisms and lessons from the recent clinical trials. Current pharmaceutical design. 2012; 18(11):1519-30.

6. Lipsy RJ. Overview of pharmacologic therapy for the treatment of dyslipidemia. Journal of Managed Care Pharmacy. 2003;9(1SuppA):9-12

7. Shabani F, Kumar L. Sensitivity analysis of CLIMEX parameters in modeling potential distribution of Phoenix dactylifera L. PloS one. 2014; 9(4):94867.

8. Abdul A, Abdul R, Che M, Al-Kahtani H, Mansor T. Date seed and date seed oil. International Food Research Journal. 2013; 20(5):2035-43.

9. Ahmed A, Arshad MU, Saeed F, Ahmed RS, Chatha SAS. Nutritional probing and HPLC profiling of roasted date pit powder. Pakistan Journal of Nutrition. 2016; 15(3):229.

10. Hasan M, Mohieldein A. In vivo evaluation of anti diabetic, hypolipidemic, antioxidative activities of Saudi date seed extract on streptozotocin induced diabetic rats. Journal of clinical and diagnostic research: JCDR. 2016; 10(3):FF06.

11. Orabi SH, Shawky SM. Effect of date palm (Phoenix dactylifera) seeds extracts on hematological, biochemical parameters and some fertility indices in male rats. Int $\mathrm{J}$ Sci Basic Appl Res. 2014; 17:137-47.

12. Kalantaripour T, Asadi-Shekaari M, Basiri M, Najar AG. Cerebroprotective effect of date seed extract (Phoenix dactylifera) on focal cerebral ischemia in male rats. Journal of Biological Sciences. 2012; 12(3):180.

13. Al-Rasheed NM, Attia HA, Mohamad RA, AlRasheed NM, Al-Amin MA, AL-Onazi A. Aqueous date flesh or pits extract attenuates liver fibrosis via suppression of hepatic stellate cell activation and reduction of inflammatory cytokines, transforming growth factor- $\beta 1$ and 
angiogenic markers in carbon tetrachlorideintoxicated rats. Evidence-based complementary and alternative medicine. 2015; 2015.

14. Bhalani U. Investigation into beneficial effect of ketoconazole in hyperlipidemia. International Journal of Research and Development in Pharmacy and Life Sciences. 2015; 3(4):6.

15. Khan T, Hamilton MP, Mundy DI, Chua SC, Scherer PE. Impact of simvastatin on adipose tissue: pleiotropic effects in vivo. Endocrinology. 2009; 150(12):5262-72.

16. Valdecantos M, Perez-Matute P, Martinez J. Obesity and oxidative stress: role of antioxidant supplementation. Revista de investigacion clinica; organo del Hospital de Enfermedades de la Nutricion. 2009; 61(2):127-39.

17. El-Sheekh MM, Hamad SM, Gomaa M. Protective effects of Spirulina on the liver function and hyperlipidemia of rats and human. Brazilian Archives of Biology and Technology. 2014; 57(1):77-86.

18. Alizadeh J, Zeki AA, Mirzaei N, Tewary S, Moghadam AR, Glogowska A, et al. Mevalonate Cascade Inhibition by Simvastatin Induces the Intrinsic Apoptosis Pathway via Depletion of Isoprenoids in Tumor Cells. Scientific Reports. 2017;7:44841.

19. Bok S-H, Lee S-H, Park Y-B, Bae K-H, Son K$\mathrm{H}$, Jeong T-S, et al. Plasma and hepatic cholesterol and hepatic activities of 3-hydroxy3-methyl-glutaryl-CoA reductase and acyl CoA: cholesterol transferase are lower in rats fed citrus peel extract or a mixture of citrus bioflavonoids. The Journal of nutrition. 1999; 129(6):1182-5.

20. Safdar MN, Kausar T, Jabbar S, Mumtaz A, Ahad K, Saddozai AA. Extraction and quantification of polyphenols from kinnow (Citrus reticulate L.) peel using ultrasound and maceration techniques. Journal of food and drug analysis. 2017; 25(3):488-500.

21. Salvamani S, Gunasekaran B, Shukor MY, Shaharuddin NA, Sabullah MK, Ahmad SA. Anti-HMG-CoA reductase, antioxidant, and anti-inflammatory activities of Amaranthus viridis leaf extract as a potential treatment for hypercholesterolemia. Evidence Based Complementary and Alternative Medicine,2016.
22. Ahmadi Y, Ghorbanihaghjo A, Argani H. The effect of statins on the organs: similar or contradictory? Journal of cardiovascular and thoracic research. 2017; 9(2):64.

23. Mocelin R, Marcon M, Santo GD, Zanatta L, Sachett A, Schönell AP, et al. Hypolipidemic and antiatherogenic effects of Cynarascolymus in cholesterol-fed rats. Revista Brasileira de Farmacognosia. 2016; 26(2):233-9.

\section{The Authors:}

Dr. Farooq Sultan,

Demonstrator,

Pharmacology Department,

Gujranwala Medical College Gujranwala.

Dr. Saba Anwar,

Women Medical Officer,

Rural Health Centre Hadali (Khushab).

Prof. Saadia Shahzad Alam,

HOD Pharmacology,

Shaikh Zayed Medical Complex, Lahore.

Dr. Hassan Farooq,

Assistant Professor,

Pharmacology Department,

Khawaja Muhammad Safdar Medical College,

Sialkot.

Dr. Ajmal Afzal,

Assistant Professor,

Pharmacology Department,

Gujranwala Medical College Gujranwala.

Dr. Moneeb Ashraf,

Assistant Professor,

Pharmacology Department,

Postgraduate Medical Institute, Lahore

\section{Corresponding Author:}

Dr. Farooq Sultan,

Demonstrator,

Pharmacology Department,

Gujranwala Medical College, Gujranwala.

E-mail: farooqsultan2000@gmail.com 